\title{
A low-voltage activated, transient calcium current is responsible for the time-dependent depolarizing inward rectification of rat neocortical neurons in vitro
}

\author{
Bernd Sutor* and Walter Zieglgänsberger \\ Clinical Neuropharmacology, Max Planck Institute for Psychiatry, Kraepelinstrasse 2, D-8000 München 40, Federal Republic of Germany
}

\begin{abstract}
Intracellular recordings were obtained from rat neocortical neurons in vitro. The current-voltage-relationship of the neuronal membrane was investigated using current- and single-electrode-voltage-clamp techniques. Within the potential range up to $25 \mathrm{mV}$ positive to the resting membrane potential (RMP: -75 to $-80 \mathrm{mV}$ ) the steady state slope resistance increased with depolarization (i.e. steady state inward rectification in depolarizing direction). Replacement of extracellular $\mathrm{NaCl}$ with an equimolar amount of choline chloride resulted in the conversion of the steady state inward rectification to an outward rectification, suggesting the presence of a voltage-dependent, persistent sodium current which generated the steady state inward rectification of these neurons. Intracellularly injected outward current pulses with just subthreshold intensities elicited a transient depolarizing potential which invariably triggered the first action potential upon an increase in current strength. Single-electrode-voltage-clamp measurements revealed that this depolarizing potential was produced by a transient calcium current activated at membrane potentials $15-20 \mathrm{mV}$ positive to the RMP and that this current was responsible for the time-dependent increase in the magnitude of the inward rectification in depolarizing direction in rat neocortical neurons. It may be that, together with the persistent sodium current, this calcium current regulates the excitability of these neurons via the adjustment of the action potential threshold.
\end{abstract}

Key words: Calcium - Sodium - Membrane conductance - Inward rectification - Action potential threshold - Neocortical neurons - Intracellular recordings Single-electrode-voltage-clamp

\section{Introduction \\ Neurons of the mammalian central nervous system (CNS) are endowed with a variety of voltage-dependent conduc- tances which are responsible for the typical nonlinear behavior of the neuronal membrane (Adams 1982). A common property inherent to most CNS neurons is the inward rectification in depolarizing direction (hereafter called depolarizing inward rectification), i.e. an increase in the steady state slope resistance occurring during a}

* Present address: Department of Neurology, Section of Neurophysiology, Baylor College of Medicine, Houston, TX 77030, USA Offprint requests to: W. Zieglgänsberger depolarization of the membrane potential (Nelson and Frank 1967; Hotson et a1. 1979; Llinás and Sugimori $1980 \mathrm{a}, \mathrm{b}$; Schwindt and Crill 1980; Connors et al. 1982; Jahnsen and Llinás 1984a, b; Stafstrom et al. 1984a, 1985; Constanti et al. 1985; Crepel and Penit-Soria 1986; Franz et al. 1986; Jahnsen 1986a). In cat neocortical neurons it has been demonstrated that this rectification is produced by a voltage-dependent, time-independent (i.e. persistent), and TTX-sensitive sodium current $\left(I_{\mathrm{NaP}}\right)$. The $I_{\mathrm{NaP}}$ is activated at membrane potential values $10-15 \mathrm{mV}$ positive to the resting membrane potential (RMP), achieves a steady state $2-4 \mathrm{~ms}$ after a step change in voltage and is not inactivating with depolarization of the membrane potential over a range of $40-50 \mathrm{mV}$ (Stafstrom et al. 1984a; 1985). The current determines the action potential threshold and the firing behaviour of layer $V$ pyramidal cells of the cat neocortex (Stafstrom et al. 1984b). A similar current with comparable functions has been shown to exist in guinea pig neocortical neurons (Connors et al. 1982), in CA1 pyramidal cells of the guinea pig hippocampus (Hotson et al. 1979), in Purkinje cells of the guinea pig cerebellum (Llinás and Sugimori $1980 \mathrm{a}, \mathrm{b}$ ), in guinea pig thalamic neurons (Jahnsen and Llinás $1984 \mathrm{a}, \mathrm{b}$ ) and in neurons of guinea pig deep cerebellar nuclei (Jahnsen 1986b). In hippocampal pyramidal cells (Hotson et al. 1979; Johnston et al. 1980) and spinal motoneurons (Schwindt and Crill 1980), a calcium current was found to be involved in the depolarizing inward rectification. The present study describes the depolarizing inward rectification of rat neocortical neurons in vitro. In addition to a persistent sodium current which mainly determines the steady state inward rectification in depolarizing direction, we found a transient voltage-dependent calcium current which was initially detectable at membrane potential levels $15-20 \mathrm{mV}$ positive to the resting potential and which produced a time-dependent enhancement of the magnitude of the depolarizing inward rectification in rat neocortical neurons.

\section{Methods}

Male Sprague-Dawley rats $(120-160 \mathrm{~g})$ were anesthetized and decapitated. The animal's brain was rapidly removed and chilled in ice-cold artificial cerebrospinal fluid (ACSF) for $30 \mathrm{~s}$ to $1 \mathrm{~min}$. Following a hemisection the hemispheres were cut in a horizontal plane perpendicular to the dorsomedial pial surface of the frontal cortex and transverse slices $(500 \mu \mathrm{m})$ were prepared from the dorsal part of each hemisphere, using the McIlwain Tissue Chopper. The slices 
were collected and stored in ACSF (continuously perfused with carbogen, i.e. $95 \% \mathrm{O}_{2}$ and $5 \% \mathrm{CO}_{2}$ ) at room temperature. Following a preincubation period of at least one hour, three slices were transferred to the recording chamber and maintained at the interface between warm moistened carbogen and ACSF. Over a period of one hour the chamber was slowly warmed to the recording temperature of $36.5^{\circ} \mathrm{C}$ $\left( \pm 0.5^{\circ} \mathrm{C}\right)$.

The ACSF consisted of (in mmol/l): $\mathrm{NaCl} 124.25, \mathrm{KCl}$ 3.5, $\mathrm{NaH}_{2} \mathrm{PO}_{4} 1.25, \mathrm{CaCl}_{2} 2.5, \mathrm{MgSO}_{4} 1.3, \mathrm{NaHCO}_{3} 26$ and glucose 10 . The solution was continuously gassed with carbogen to give a final $\mathrm{pH}$ of 7.4. The measured value of the solution's osmolarity was $305 \mathrm{mOsm}$. When manganese $\left(\mathrm{MnCl}_{2}\right)$, cobalt $\left(\mathrm{CoCl}_{2}\right)$ or cadmium $\left(\mathrm{CdCl}_{2}\right)$ were added to the ACSF, $\mathrm{NaH}_{2} \mathrm{PO}_{4}$ was omitted, $\mathrm{MgSO}_{4}$ replaced by $\mathrm{MgCl}_{2}$ and the calcium concentration lowered to $0.5 \mathrm{mmol} / 1$. ACSF containing cadmium was buffered with N-2-hydroxyethylpiperazine- $\mathrm{N}^{\prime}$-2-ethanesulfonic acid (HEPES, $10 \mathrm{mmol} / 1 ; \mathrm{pH} 7.4)$. In some experiments $\mathrm{NaCl}$ was replaced with choline chloride. Tetraethylammonium (TEA, $10 \mathrm{mmol} / \mathrm{l}$ ) was added to the bathing solution and an equimolar amount of $\mathrm{NaCl}$ was removed in order to keep the osmolarity of the ACSF constant.

Intracellular recordings were made using glass microelectrodes. The electrodes were pulled from thick-walled borosilicate glass tubings and filled with $4 \mathrm{~mol} / 1$ potassium acetate (adjusted to $\mathrm{pH} 7.2$ with acetic acid). The resistance of these electrodes ranged between 50 and $90 \mathrm{M} \Omega$. In a few instances the electrodes were filled with $1 \mathrm{~mol} / \mathrm{l} \mathrm{CsCl}$ dissolved either in destilled water or in $4 \mathrm{~mol} / \mathrm{l}$ potassium acetate ( $\mathrm{pH} 7.2)$.

Intracellular signals were recorded using a npi SEC 1L single electrode current- and voltage-clamp amplifier (Polder, Tamm, FRG). With this amplifier intracellular current injection was carried out via a bridge circuit or else a switched clamp system consisting of a high frequency alternation between potential measurement and current injection. During employment of the switched current-clamp mode the output signal of the headstage amplifier was continuously monitored on a separate oscilloscope and the recorded voltage transients were adjusted, using capacity neutralization, in order to approach a rectangular form as close as possible. The switching frequency was then set to enable voltage measurements to be made after the complete decay of each voltage transient. Switching frequencies between 14 and $18 \mathrm{kHz}$, at a duty cycle of $25 \%$, could be used. Following the correct adjustment of the current-clamp system, the amplifier was switched to its single electrode voltage-clamp mode (SEVC). Initially, the membrane potential was clamped to the neuron's RMP, the gain was increased to the maximum value possible and, if necessary, the capacity compensation was readjusted. Electrodes for voltage-clamp recordings were carefully selected, it being mandatory to have low resistances (max. $80 \mathrm{M} \Omega$ ), no detectable polarization during prolonged current injections $(2-3 \mathrm{nA}$ for $2 \mathrm{~s})$ and neglectable rectification. The electrode test was performed with the electrode tip immersed in the slice. When combined with the above described electrodes, the properly tuned amplifier responded to voltage-clamp command steps of $\pm 50 \mathrm{mV}$ with a maximum settling time of $2 \mathrm{~ms}$, without any detectable deviations from the desired command level. During voltage-clamp experiments, the electrophysiological properties of the neurons and the properties of the recording electrodes were regularly checked for any changes, using the bridge or the switched current clamp mode.

The recorded signals were displayed on an oscilloscope and either stored on magnetic tape (FM tape recorder bandwidth: DC to $2.5 \mathrm{kHz}$ ) or digitized on-line using a LSI $11 / 73$ computer (digitizing rate $61 \mu \mathrm{s}$ to $2 \mathrm{~ms} /$ point). The membrane potential was continuously monitored on a digital voltmeter and recorded on a chart writer. For analysis the signals stored on tape were either replayed on a digital oscilloscope and plotted using a X-Y-plotter, or digitized with the computer and plotted by means of a matrix printer. Membrane currents were filtered at $0.5-1.0 \mathrm{kHz}$.

Membrane currents evoked by voltage command steps were corrected for the steady state leakage current $\left(I_{\mathrm{L}}\right)$, which was assumed to be a linear function of the voltage change (V) in the potential range investigated $(-100$ to $-30 \mathrm{mV}$; see Stevens 1980). The membrane potential was clamped to the resting potential and the leakage conductance $\left(g_{\mathrm{L}}\right)$ was determined by applying de- and hyperpolarizing voltage steps $(150 \mathrm{~ms}, 2-5 \mathrm{mV})$. The amplitude of the current response was measured $145 \mathrm{~ms}$ after the onset of the step (for each measurement at least 10 single recordings were averaged). The slope of the resulting current-voltage-curve, which was found to be linear in all neurons tested $(n=$ 27), corresponded to $g_{\mathrm{L}}$. For each voltage step $I_{\mathrm{L}}$ was then calculated from Ohm's law and substracted from the corresponding current response, using the computer.

During the experiments a "threshold current intensity" was considered to be the current strength necessary to evoke one action potential by the injection of an outward current pulse of $150 \mathrm{~ms}$ in duration. The current strength was accepted as threshold intensity, if $10-15$ consecutive pulses generated an action potential without one failure (pulse frequency $0.25 \mathrm{~Hz}$ ). Consequently, a "just subthreshold current intensity" was defined as a current strength which was somewhat smaller than the threshold current (usually $0.1 \mathrm{nA}$ ), and which never produced an action potential when injected into the cell.

\section{Results}

Intracellular recordings were obtained from 94 neurons located in the superficial layers (II and III) of the neocortex. The injection of the fluorescent dye Lucifer Yellow into 24 neurons (not included in the above sample) identified 21 of these as pyramidal cells (Sutor 1986). The neurons had a resting membrane potential (RMP) of $-77.6 \pm 3.1 \mathrm{mV}$ (mean $\pm \mathrm{SD}$ ) and a membrane time constant of $8.9 \pm 3.3 \mathrm{~ms}$ $(n=20)$. The steady state membrane input resistance $\left(R_{\mathrm{N}}\right)$ was determined either from the slope of the current-voltagecurve (slope resistance) at the intercept of the coordinate axes (i.e. at RMP; see Fig. 1B), or by injecting small hyperpolarizing current pulses $(0.1-0.5 \mathrm{nA}$ for $150 \mathrm{~ms})$ and measuring the steady state voltage deviation $145 \mathrm{~ms}$ after the onset of the pulse. Results yielded by both methods were not significantly different and were therefore combined to give a mean $R_{\mathrm{N}}$ of $27.9 \pm 8.7 \mathrm{M} \Omega$.

The current-voltage-relationship of the neuronal membrane was determined in all neurons by injecting inward and subthreshold outward current pulses using variable current strengths (Fig. 1 A). The amplitudes of the current-induced voltage deflections were measured just before the offset of 

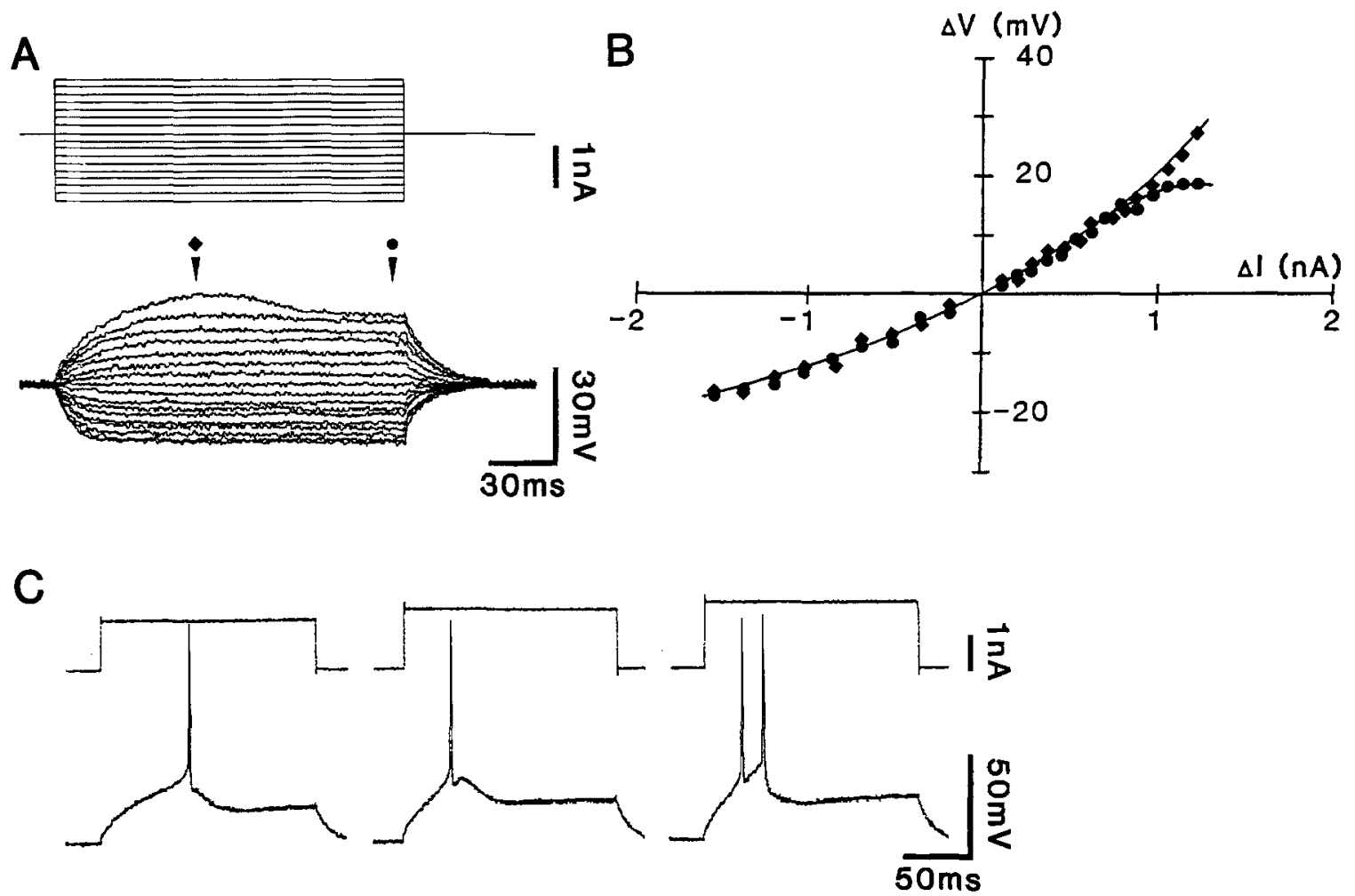

Fig. $1 \mathrm{~A}-\mathrm{C}$. Determination of the IV-relationship of an intracellularly recorded neocortical neuron (RMP: $-78 \mathrm{mV}$, recording electrode contained potassium acetate). A De- and hyperpolarizing current pulses (150 $\mathrm{ms}$ in duration) of variable amplitudes were injected and the corresponding voltage responses measured at the time points indicated by the arrowheads (diamond: $60 \mathrm{~ms}$, and dot: $144 \mathrm{~ms}$ after onset). The consecutive recordings were superimposed. In this and all figures in which current clamp recordings are shown, the upper traces represent the current monitor (the zero-current trace was adjusted to the extracellular zero-potential) and the lower traces the voltage signals. B IV-curves resulting from the measurements depicted in A. C Injection of depolarizing current pulses (150 ms in duration) with threshold $(1.4 \mathrm{nA}$, left $)$ and suprathreshold intensities $(1.7 \mathrm{nA}$, center, and $1.9 \mathrm{nA}$, right). Note the depolarizing afterpotential following the action potential elicited by the injection of an outward current with $1.7 \mathrm{nA}$ (center). Same cell as in $\mathbf{A}$ and $\mathbf{B}$

the current pulse (Fig. 1 A, dots) and at a time corresponding to the time to peak of a transient depolarizing potential which invariably occurred in response to the injection of just subthreshold outward current pulses (Fig. $1 \mathrm{~A}$, diamond). The resulting current-voltage-curves (IV-curves, Fig. $1 \mathrm{~B}$ ) revealed inward rectification in both the hyperpolarizing and subthreshold depolarizing direction (i.e. decrease in slope resistance with hyperpolarization and increase in slope resistance with depolarization respectively). The hyperpolarizing inward rectification could be observed even at membrane potentials only slightly negative to the RMP (approx. $5 \mathrm{mV}$ ). In the potential range investigated $(20-30 \mathrm{mV}$ negative to the RMP) the reduction in slope resistance was found to increase steadily with hyperpolarization. Furthermore, in this potential range and within $150 \mathrm{~ms}$ after onset of the current pulse, the hyperpolarizing inward rectification was time-independent (Fig. 1 B, dots and diamonds). Following the injection of inward current pulses, the potential reached a steady state level approximately $15-20 \mathrm{~ms}$ after the onset of the pulse (Fig. 1 A). The attainment of the steady state was faster than predicted from a single exponential function, suggesting the presence of equalizing currents (Rall 1977). In 20 neurons the existence of such currents was proved by the determination of the first equalizing time constant, using the method described by Rall (1969). The mean value was found to be $1.1 \pm 0.4 \mathrm{~ms}$. According to Rall's model of the neuron (Rall 1969, 1977), the equivalent electrotonic length
(L) was calculated to be 1.13 space constants $( \pm 0.23 ; n=$ 20 ), suggesting that the neurons of the superficial layers of the rat frontal cortex are electrotonically compact (Vogt and Gorman 1982; Stafstrom et al. 1984c).

Within the potential range up to $15 \mathrm{mV}$ positive to the RMP, the slope resistance increased with depolarization and there was no indication of a time-dependent event (steady state inward rectification in depolarizing direction; see Fig. $1 \mathrm{~B}$, dots and diamonds). However, upon injection of subthreshold outward current pulses with intensities which produced voltage deflections larger than $15 \mathrm{mV}$, the neurons responded with a transient depolarizing potential (tDP, see Fig. 1 A, diamonds) followed by a potential sag (Fig. 1 A; see also Stafstrom et al. 1984a). The amplitude of the tDP, which had a time to peak of $24-61 \mathrm{~ms}$ and a duration of $43-105 \mathrm{~ms}$, was gradually increasing upon enhancement of the current intensity, thereby causing a further increase in slope resistance with depolarization (Fig. 1 B, diamonds). In contrast, the potential sag following the tDP led to a decrease in slope resistance with depolarization (Fig. $1 \mathrm{~B}$, dots).

Using threshold intensity, the tDP invariably gave rise to the first action potential, generated by the neurons in response to the injection of depolarizing current pulses (Fig. 1C, left). The mean amplitude of these action potentials was $100.6 \pm 7.6 \mathrm{mV}$ with a mean duration of $0.81 \pm 0.22 \mathrm{~ms}$ (measured at half-maximal amplitude). A slight increase in the current strength resulted in a shortening 

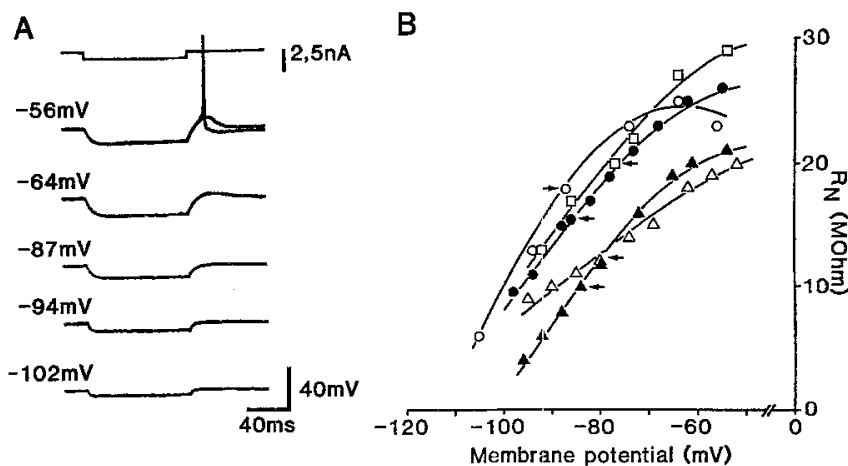

Fig. 2 A, B. Measurements of the steady state input resistance $\left(R_{\mathrm{N}}\right)$ of a neuron (RMP: $-83 \mathrm{mV}$ ) at different membrane potentials. A The $R_{\mathrm{N}}$ was determined by injecting an inward current pulse $(100 \mathrm{~ms}, 0.8 \mathrm{nA})$ and measuring the corresponding voltage deviation just before the offset of the current pulse. The different membrane potentials were adjusted by the injection of de- and hyperpolarizing direct currents. The recordings were performed using the switched current-clamp mode, the recording electrode was filled with potassium acetate. At $-56 \mathrm{mV}$ two single traces were superimposed. Note the action potential elicited on top of a transient depolarizing potential following the current-induced hyperpolarization. In this figure, the current monitor does not correspond to the extracellular zero-potential. B Graphical presentation of similar measurements obtained from five neurons (different symbols, RMPs are indicated by the arrows). The $R_{\mathrm{N}}$ was calculated according to Ohm's law and plotted against the membrane potential

of the spike latency and in the occurrence of an afterdepolarization (Fig. 1C, center) which in turn triggered an action potential upon further enhancement of the current intensity (Fig. $1 \mathrm{C}$, right). Depolarizing current pulses, with intensities between 1.5 and 2 times the threshold intensity, evoked a repetitive discharge of action potentials associated with an adaptation of the spike frequency.

Stafstrom et al. (1984a) suggested that a similar tDP in cat neocortical neurons is caused by the almost instantaneous activation of a voltage--dependent, persistent sodium current $\left(I_{\mathrm{NaP}}\right)$ which is countered by delayed activated potassium outward currents. To test this hypothesis, experiments were carried out in order to establish the existence of a similar sodium current in rat neocortical neurons. At different membrane potentials, the $R_{\mathrm{N}}$ was determined using inward current pulses with a duration of $100-150 \mathrm{~ms}$ (Fig. 2A). The amplitude of the corresponding voltage response was measured just before the offset of the current pulse, the $R_{\mathrm{N}}$ was calculated and plotted against the membrane potential (Fig. 2B; see also Hotson et al. 1979 and Connors et al. 1982). From the graph in Fig. 2B it can be seen that, with respect to the RMP (indicated by the arrowheads), the membrane resistance was increasing with depolarization and decreasing with hyperpolarization. According to Connors et al. (1982) a rectification ratio (RR) was calculated from the quotient of the $R_{\mathrm{N}}$ determined at a membrane potential of $-55 \mathrm{mV}( \pm 2 \mathrm{mV})$ and the $R_{\mathrm{N}}$ measured at $-80 \mathrm{mV}( \pm 2 \mathrm{mV})$. The mean value of the RR was found to be $1.75 \pm 0.39(n=32)$. Following a $82 \%$ reduction in the extracellular sodium concentration, the fast action potential was abolished (Fig. $3 \mathrm{~A}$ and $\mathrm{B}$ ), the synaptic transmission blocked, and the membrane potential was found to be depolarized by $6-11 \mathrm{mV}$. Furthermore, the depolarizing inward rectification (Fig. 3A) converted to an

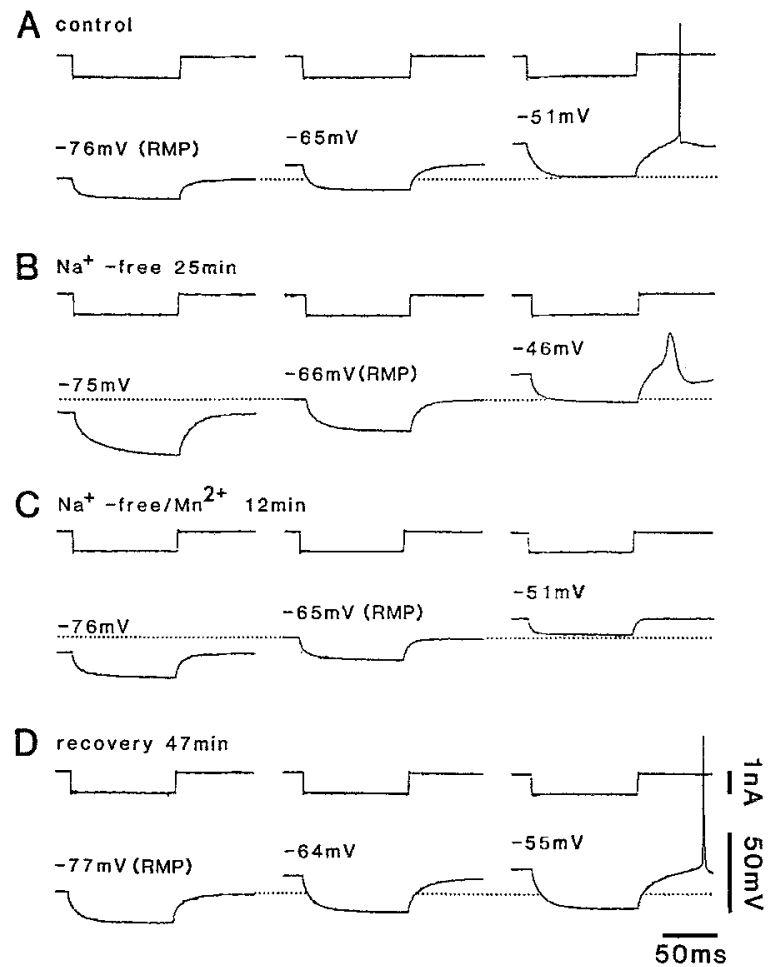

Fig. 3A-D. Dependence of the depolarizing steady state inward rectification on the extracellular sodium concentration. A Determination of the $R_{\mathrm{N}}$ at different membrane potentials as described in the legend to Fig. 2 (hyperpolarizing current pulse: $100 \mathrm{~ms}, 1 \mathrm{nA}$ ). Note the increase in $R_{\mathrm{N}}$ (indicated by the increase in the currentinduced voltage change) with depolarization. B Recordings from the same neuron after $25 \mathrm{~min}$ following the replacement of the ACSF's $\mathrm{NaCl}$ concentration $(124.25 \mathrm{mmol} / \mathrm{l})$ by an equimolar amount of choline chloride ("Na ${ }^{+}$-free"). The RMP depolarized by $10 \mathrm{mV}$ (from $-76 \mathrm{mV}$, see $\mathrm{A}$, to $-66 \mathrm{mV}$ ) and the $R_{\mathrm{N}}$ decreased with depolarization and increased with hyperpolarization. Note the slow depolarizing potential evoked at a membrane potential of $-46 \mathrm{mV}$. C These slow depolarizing potentials were blocked upon addition of manganese $(4 \mathrm{mmol} / \mathrm{l})$ to the " $\mathrm{Na}^{+}$-free" solution, but the rectification behaviour remained unaltered. D These effects were reversible within $47 \mathrm{~min}$ after replacing the " $\mathrm{Na}^{+}$-free" and manganese-containing medium with normal ACSF. (Recording electrode contained potassium acetate)

outward rectification (Fig. 3B) with a RR of $0.84 \pm 0.27$ $(n=7)$. Upon passive depolarization of the membrane potential to values positive to $-50 \mathrm{mV}$ (Fig. 3B) the cells generated spontaneous slow action potentials which were blocked by manganese added to the bathing medium $\left(\mathrm{MnCl}_{2}, 4 \mathrm{mmol} / 1 ; n=4\right.$; Fig. $\left.3 \mathrm{C}\right)$. Since manganese did not influence the steady state rectifying behaviour of the neuronal membrane, neither in the absence (Fig. 3C) nor in the presence of sodium chloride in the bathing solution, we suggest that, under normal conditions, the steady state inward rectification in depolarizing direction of rat neocortical neurons is mainly determined by a persistent sodium current. In addition, upon reduction of the extracellular potassium concentration to $1.25 \mathrm{mmol} / \mathrm{l}$, or following the injection of cesium ions into the neurons, the depolarizing steady state inward rectification was found to be enhanced $(\mathrm{RR}=3.3 \pm 0.6, n=7$; Sutor 1986), probably due to the lack of potassium currents counterbalancing the persistent sodium current (Connors et al. 1982). 
A

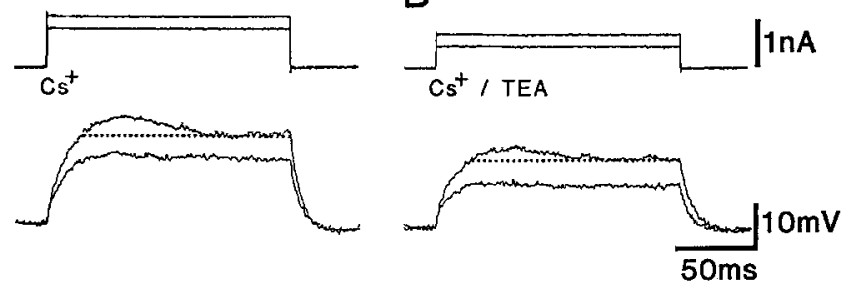

Fig. 4A, B. The transient depolarizing potential was not abolished by cesium ions and TEA. A Intracellular recordings from a neuron $(\mathrm{RMP}=-83 \mathrm{mV}$ ) by means of an electrode containing $1 \mathrm{~mol} / 1$ $\mathrm{CsCl}$ dissolved in $4 \mathrm{~mol} / 1$ potassium acetate $(\mathrm{pH} 7.2$ ). Superposition of voltage responses (lower traces) evoked by the injection of outward current pulses (150 ms, upper traces) with $0.9 \mathrm{nA}$ and $1.2 \mathrm{nA}$ (just subthreshold intensity). A depolarizing current pulse with $1.3 \mathrm{nA}$ elicited a prolonged action potential. B In the same neuron, the addition of TEA produced a depolarization of $5 \mathrm{mV}$ and a decrease in the current strength necessary to evoke a spike $(0.9 \mathrm{nA})$. The injection of a depolarizing current pulse with just subthreshold intensity $(0.8 \mathrm{nA})$ evoked a clear, although reduced tDP, which disappeared upon reduction of the current strength to $0.5 \mathrm{nA}$. The figure shows the superposition of the voltage responses evoked by the injection of current pulses with 0.5 and $0.8 \mathrm{nA}$. The dotted lines indicate the potential levels attained just before the offset of the current pulses

Experiments, in which cesium ions and TEA were used to suppress potassium currents, however, provided the first indications that the tDP is probably not exclusively the result of an interplay between a persistent sodium current and delayed activated potassium outward currents. Intracellular injections of cesium ions from electrodes containing $1 \mathrm{~mol} / \mathrm{l}$ $\mathrm{CsCl}$ or addition of TEA $(10 \mathrm{mmol} / \mathrm{l})$ to the ACSF prolonged the duration of action potentials 15- to 100 -fold (see Howe et al. 1987a). The cesium- and TEA-induced prolongation of the spike was reversibly reduced by manganese $\left(\mathrm{MnCl}_{2}, 4 \mathrm{mmol} / \mathrm{l}\right.$, added to the ACSF) and cobalt $\left(\mathrm{CoCl}_{2}, 2 \mathrm{mmol} / 1\right.$, added to the ACSF), indicating both the presence of a calcium current, activated during directly evoked action potentials (Howe et al. 1987a), and the ability of cesium ions and TEA to effectively block potassium currents under these experimental conditions.

Following the injection of cesium ions, the neurons still generated tDPs in response to just subthreshold depolarizing current pulses (Fig. 4A). The amplitude of these tDPs diminished and disappeared upon a reduction in the injected current strength (Fig. 4A). The additional application of TEA (10 mmol/l) led to a slight depolarization of the membrane potential $(3-8 \mathrm{mV})$, to an increase in membrane resistance $(30-50 \%)$, and, consequently, to a decrease in the current intensity necessary to evoke action potentials. However, in the presence of both cesium and TEA, the tDP evoked by just subthreshold outward current pulses was found to be reduced by $25-40 \%$, but in no case was it completely abolished (Fig. 4B). These experiments indicate that the potential sag following the tDP was not solely produced by the delayed activation of cesium- and/or TEAsensitive outward currents which act to partially repolarize a depolarizing potential change evoked by an instantaneously activated, inward rectifying, persistent sodium current. Consequently, the tDP is an actively generated potential, suggesting the presence of a transient inward current which is activated in the subthreshold potential range.
To test this hypothesis, single-electrode-voltage-clamp recordings were performed in 27 neurons. Figure $5 \mathrm{~A}$ depicts a representative example of the measurements. The neuron's membrane potential was voltage-clamped to its RMP. Deand hyperpolarizing voltage command steps were applied and the corresponding current response measured at the times indicated by the arrowheads (Fig. 5 A, dot and square, only depolarizing voltage steps are shown). In agreement with the results obtained from current-clamp recordings, an increase in the slope conductance was observed upon hyperpolarization of the membrane potential (Fig. 5B, dots and squares). The substraction of the leakage current revealed a persistent, net inward current evoked by voltage steps to command potentials more negative than $-95 \mathrm{mV}$ (Fig. 5B, dots and squares). Since under the given experimental conditions the potassium equilibrium potential, calculated from the Nernst equation (intracellular potassium concentration $110-150 \mathrm{mmol} / \mathrm{l}$ ), ranged between -93 and $-101 \mathrm{mV}$, this finding suggests that the hyperpolarizing inward rectification is mainly the result of the activation of a potassium conductance (Constanti and Galvan 1983; Mayer and Westbrook 1983).

In the potential range up to $20 \mathrm{mV}$ positive to the RMP, depolarizing voltage command steps produced persistent outward currents, the amplitude of which gradually increased with depolarization (Fig. 5A and B). In the same potential range, the slope conductance (represented by the slope of the IV-curve, Fig. 5B) decreased with depolarization, suggesting the presence of an inward rectifying conductance. Following voltage steps to command potentials more positive than $-55 \mathrm{mV}$, a transient reduction in the outward current response became obvious (Fig. 5A, square). This time-dependent decrease in the step-evoked outward current produced an IV-curve with a region of negative slope conductance in the range between -50 and $-40 \mathrm{mV}$ (Fig. 5B, squares). In contrast, the steady state current response measured just before the offset of the voltage step (Fig. 5A, dot) resulted in an IV-curve, the slope of which increased with depolarization (Fig. 5B, dots). Upon substraction of the leakage current, it became clear that depolarizing voltage steps up to $25 \mathrm{mV}$ in amplitude evoked a persistent, net inward current (Fig. 5C, dots and squares) which yielded an IV-curve with a region of negative slope conductance in the potential range between -80 and $-60 \mathrm{mV}$ (Fig. 5D, dots and squares). Voltage steps to command potentials more positive than $-55 \mathrm{mV}$ elicited a transient net inward current $\left(I_{t}\right)$ superimposed on the persistent inward current (Fig. 5C, square). The time to peak of the $I_{1}$ was found to be $20-$ $60 \mathrm{~ms}$ and the duration $50-100 \mathrm{~ms}$. The amplitude of the $I_{t}$ gradually increased with depolarization, leading to a further increase in the IV-curve's negative slope (Fig. 5C and D, squares). The slope of the IV-curve determined just before the offset of the voltage step declined at membrane potentials more positive than $-45 \mathrm{mV}$, indicating a weak activation of outward currents at these membrane potentials (Fig. 5C and $\mathrm{D}$, dots).

The $I_{\mathrm{t}}$ could be evoked in neurons intracellularly recorded using electrodes containing $1 \mathrm{~mol} / \mathrm{l} \mathrm{CsCl}$ and in the presence of $10 \mathrm{mmol} / \mathrm{l} \mathrm{TEA}$ in the bathing medium (not shown). However, on addition of the calcium channel blockers cadmium or cobalt $\left(\mathrm{CdCl}_{2}, 1 \mathrm{mmol} / 1, n=2 ; \mathrm{CoCl}_{2}\right.$, $2 \mathrm{mmol} / 1, n=2$; respectively; see Hagiwara and Byerly $1983)$ to the ACSF, the amplitude of the $I_{1}$ was found to be reversibly reduced by $50-70 \%$ (Fig. $6 \mathrm{~A}$ ), indicating that 

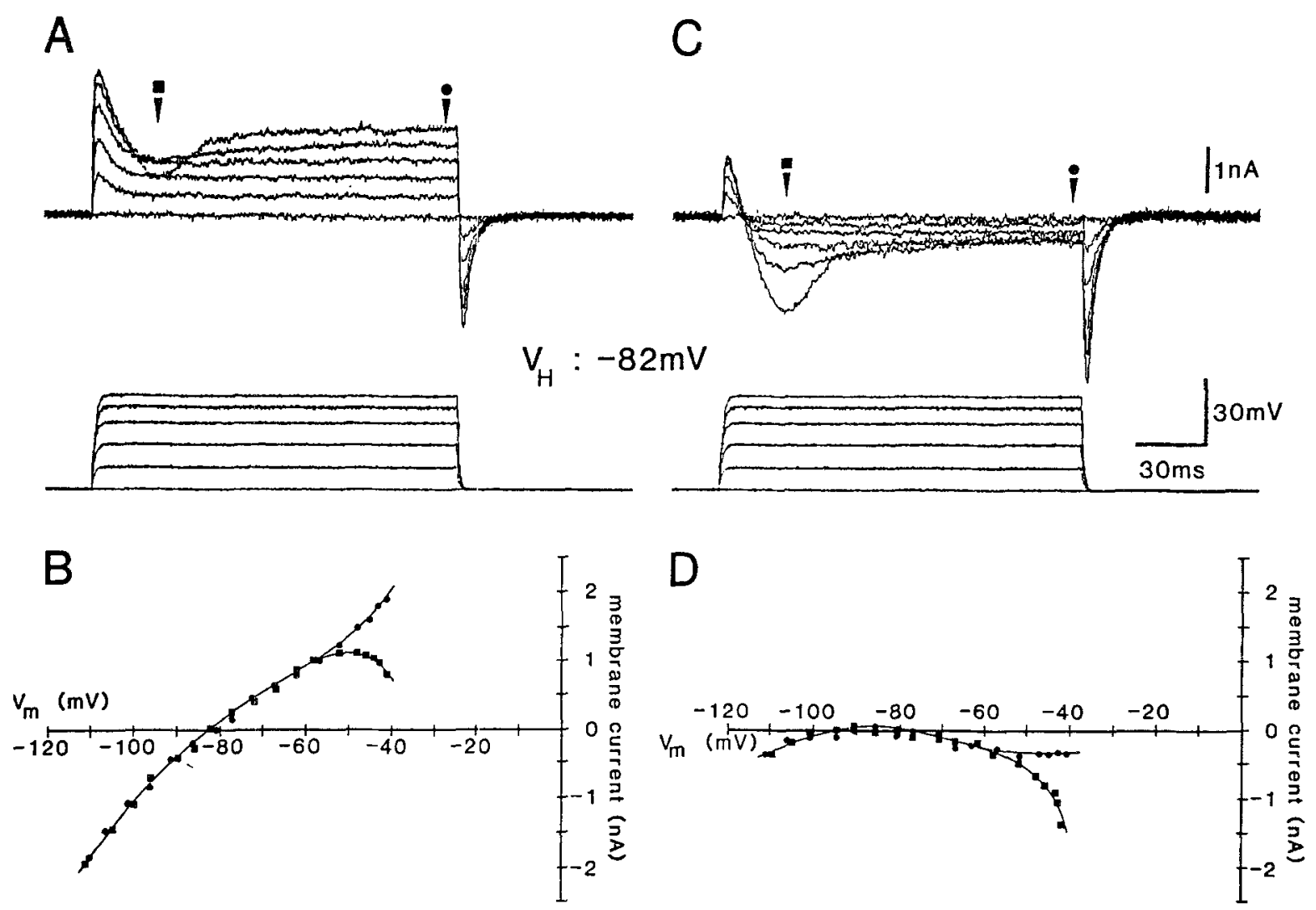

Fig. 5A-D. Determination of the IV-relationship of a neocortical neuron (RMP: $-82 \mathrm{mV}$ ) using the SEVC. (Recording electrode filled with potassium acetate.) A The neuron's membrane potential was clamped to its RMP, i.e. holding potential $\left(V_{\mathrm{H}}\right)=-82 \mathrm{mV}$. Depolarizing voltage command steps were applied (150 ms, lower traces) and the membrane currents measured at the time points indicated (upper traces; square: $27 \mathrm{~ms}$, and dot: $144 \mathrm{~ms}$ after onset of the voltage step). The consecutive recordings were superimposed. Each trace represents the average of three single sweeps. B IV-curves of the neuron obtained from measurements using de- and hyperpolarizing voltage steps. The different symbols correspond to the time points of measurement in A. Note the differences of the IV-curves at membrane potentials positive to $-55 \mathrm{mV}$. C Net membrane inward currents (corrected for the leakage current) induced by depolarizing voltage steps. D IV-curves determined from the net membrane currents. The different symbols correspond to the time points of measurement as indicated in $\mathbf{C}$ (identical to those in A)

the $I_{\mathrm{t}}$ was mainly caused by the activation of a calcium conductance.

A characteristic property of the $I_{t}$ was found to be a decline of its amplitude by $40-60 \%$, upon depolarization of the holding potential (voltage-dependent inactivation; see Carbone and Lux 1984). In the example shown in Fig. 6B, a voltage step from a holding potential of $-80 \mathrm{mV}$ to a command potential of $-40 \mathrm{mV}$ produced an $I_{\mathrm{t}}$ with an amplitude of $1.3 \mathrm{nA}$ (including the amplitude of the persistent inward current; Fig. 6B, left). A step from a holding potential of $-60 \mathrm{mV}$ to $-40 \mathrm{mV}$, however, elicited an $I_{\mathrm{t}}$ with an amplitude of only $0.6 \mathrm{nA}$ (Fig. 6B, center).

The coincidence of the time courses of the $I_{t}$ and of the tDP is one argument in favor of the conclusion that the $I_{t}$ generated the transient depolarizing potential evoked by just subthreshold outward current pulses. If this was the case, then the tDP had to be suppressed by calcium channel blockers, since the $I_{\mathrm{t}}$ was shown to be cadmium- and cobaltsensitive. Figure 7 depicts intracellular recordings from a neuron in the presence and absence of cadmium. A depolarizing current pulse with $0.9 \mathrm{nA}$ elicited an action potential with a voltage threshold $31 \mathrm{mV}$ positive to the RMP ( $-76 \mathrm{mV}$, Fig. 7 A, right). To the injection of a just subthreshold outward current pulse $(0.8 \mathrm{nA})$, the neuron responded with a prominent tDP (Fig. 7A, center), the amplitude of which decreased with further reduction in the injected current strength (Fig. 7A, left). In the presence of cadmium ( $1 \mathrm{mmol} / \mathrm{l}$ added to a HEPES - buffered bathing medium), a just subthreshold current pulse $(0.9 \mathrm{nA})$ failed to evoke a tDP (Fig. 7B, center), the threshold current intensity necessary to generate an action potential increased to $1.1 \mathrm{nA}$ and the voltage threshold was found to be $37 \mathrm{mV}$ positive to the RMP $(-77 \mathrm{mV}$, Fig. $7 \mathrm{~B}$, right). All these effects reversed upon replacing the cadmium-containing medium with ACSF (Fig. 7C).

\section{Discussion}

In the present study, the depolarizing inward rectification detectable in rat neocortical neurons in vitro was analyzed using current- and voltage-clamp techniques. Intracellular recordings were obtained from neurons located in layers II and III of the frontal cortex. The electrophysiological properties of these cells (i.e. RMP, $R_{\mathrm{N}}$, time constant, and action potential amplitude) were similar to those reported for neocortical neurons in comparable preparations (Connors et al. 1982; Vogt and Gorman 1982; Stafstrom et 

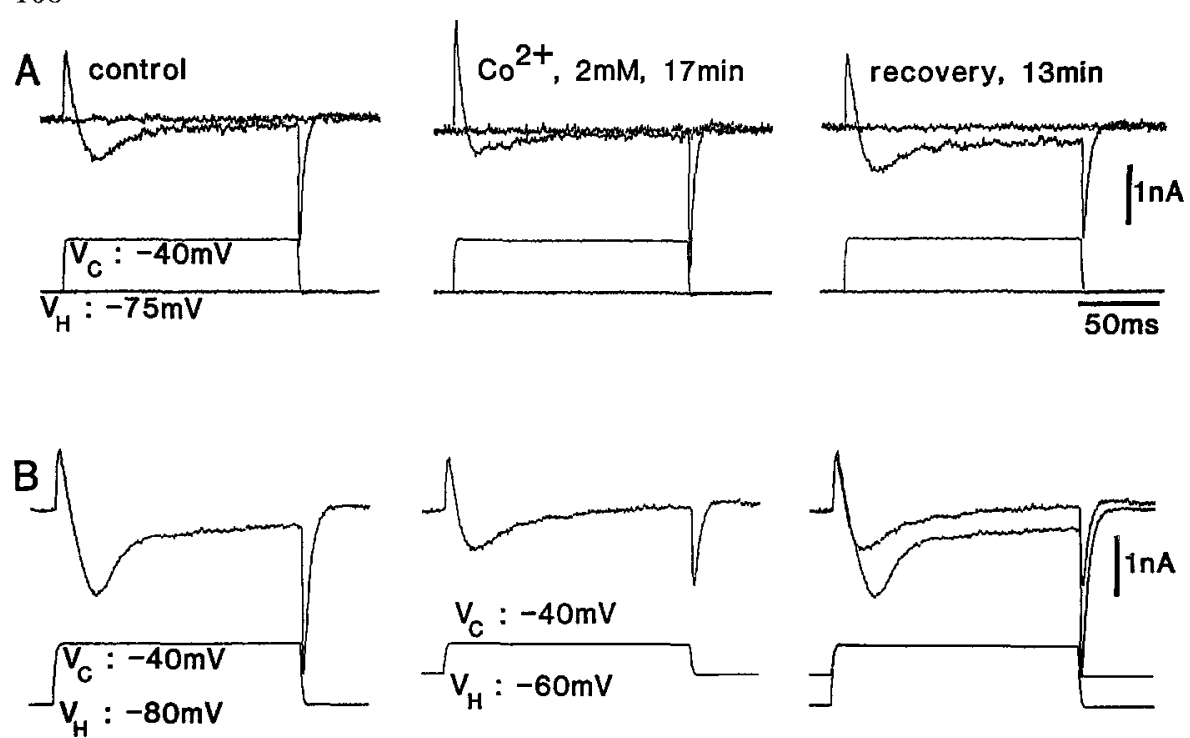

Fig. 6A, B. The transient inward current was reversibly diminished by calcium channel blockers and it inactivated with depolarization of the holding potential. A In a neuron (RMP $=-74 \mathrm{mV}$; recording electrode filled with potassium acetate) a voltage step from a holding potential $\left(V_{\mathrm{H}}\right)$ of $-75 \mathrm{mV}$ to a command potential $\left(V_{\mathrm{C}}\right)$ of $-40 \mathrm{mV}$ evoked an $I_{1}$ (peak amplitude $0.7 \mathrm{nA}$, control), the amplitude of which was reduced by $0.4 \mathrm{nA}$ following the addition of cobalt $(2 \mathrm{mmol} / \mathrm{l})$ to the bathing medium (center). Cobalt's depressing effect was reversible (right). Membrane currents were corrected for $I_{\mathbf{L}}$ (also in B). B Voltage-clamp measurements obtained from another neuron $(\mathrm{RMP}=$ $-82 \mathrm{mV}$; recording electrode filled with potassium acetate). A voltage step from $V_{\mathrm{H}}=-80 \mathrm{mV}$ to $V_{\mathrm{C}}=-40 \mathrm{mV}$ (left) produced an $I_{\mathrm{t}}$ the amplitude of which was found to be reduced by $54 \%$ when the membrane potential was stepped from $V_{\mathrm{H}}=-60 \mathrm{mV}$ to $V_{\mathrm{C}}=-40 \mathrm{mV}$ (center). In the picture on the right both recordings were superimposed.

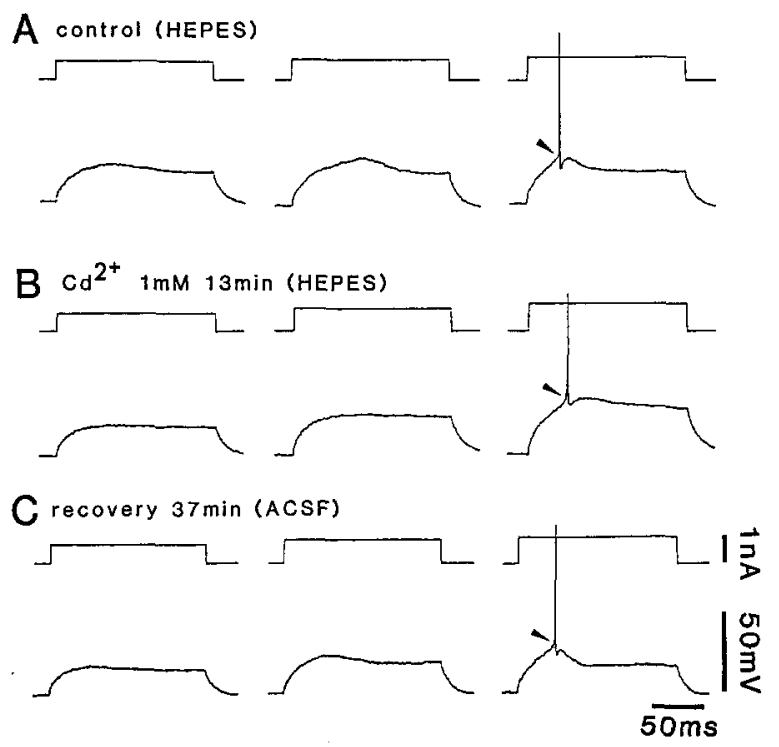

Fig. 7A-C. Calcium channel blockers suppressed the transient depolarizing potential and increased both the current necessary to evoke an action potential and the voltage threshold of the spike. $(\mathrm{RMP}=-76 \mathrm{mV}$; recording electrode filled with potassium acetate.) A Injection of outward current pulses with amplitudes of $0.7 \mathrm{nA}$ (left), $0.8 \mathrm{nA}$ (center) and $0.9 \mathrm{nA}$ (right). Note the small tDP occurring in response to the current pulse with $0.7 \mathrm{nA}$ (left) and the larger one induced by injection of $0.8 \mathrm{nA}$ (center). The arrowhead (right) points to the spike threshold $(-45 \mathrm{mV})$. During the control recordings the slices were perfused with a HEPES-buffered solution. B In the presence of cadmium $(1 \mathrm{mmol} / 1$, added to the bathing medium), a just subthreshold current pulse failed to evoke a tDP (center). The current necessary to elicit a spike increased to $1.1 \mathrm{nA}$, and the spike threshold was found to be enhanced by $6 \mathrm{mV}$ (right, see arrowhead). C Upon replacing the HEPES-buffered, cadmiumcontaining solution by normal ACSF, the described effect reversed within $37 \mathrm{~min}$ (spike threshold: $-48 \mathrm{mV}$ ) al. 1984a; McCormick et al. 1985; Franz et al. 1986). In addition, in a previous study, the RMP values were found to be normally distributed ( $n=248$; Sutor 1986) and, furthermore, the RMP did not correlate with the membrane input resistance determined at RMP, indicating that the neuron population investigated was quite homogeneous and that the percentage of neurons with a significant, nonspecific current leak produced by the microelectrode was rather small (Connors et al. 1982).

According to McCormick et al. (1985) these neurons could be classified as regular-spiking cells. The action potentials elicited by depolarizing current injection had a duration of $0.8 \mathrm{~ms}$. Upon injection of suprathreshold current pulses, the cells responded with a repetitive spike discharge which showed frequency adaptation (Sutor 1986), and the spike-train was followed by a potassium-dependent afterhyperpolarization on termination of the current pulse (Howe et al. 1987b). Furthermore, the majority of neurons in a representative sample were morphologically identified as pyramidal cells (Sutor 1986; see also McCormick et al. 1985). Therefore, we may conclude that most of the neurons investigated were pyramidal cells located in layers II and III of the rat frontal cortex.

A common property of these neurons is the marked inward rectification in both the hyperpolarizing and subthreshold depolarizing direction. The IV-curves determined by injection of inward and outward current pulses revealed an increase in slope resistance with depolarization and a decrease with hyperpolarization (see Fig. 1 A and B). These results were confirmed by the voltage-clamp measurements, where the slope conductance decreased with depolarization and increased with hyperpolarization (see Fig. 5B and D). Since hyperpolarizing voltage steps to membrane potentials negative to $-95 \mathrm{mV}$ evoked net inward currents, it seems likely that a potassium conductance is activated with hyper- 
polarization, thereby producing inward rectification. A consistent finding was an increase in the steady state input resistance with hyperpolarization upon substitution of the ASCF's $\mathrm{NaCl}$ concentration with choline chloride (see Fig. 3B). Similar observations were made with mouse spinal sensory ganglion neurons (Mayer and Westbrook 1983) and rat cerebellar Purkinje cells (Crepel and Penit-Soria 1986) and it was suggested that the current responsible for the hyperpolarizing inward rectification in these neurons (termed $I_{h}$, Mayer and Westbrook 1983) is a mixed sodiumpotassium-current. From the data available at present, we cannot decide whether or not the hyperpolarizing inward rectification in rat neocortical neurons is produced by a current similar to the $I_{\mathrm{h}}$. But, in contrast to the authors mentioned above, we found no time-dependence of the hyperpolarizing inward rectification in all neurons tested using both the current- and the voltage-clamp technique.

The depolarizing inward rectification in rat neocortical neurons results from at least two different processes, a timedependent and a time-independent one. Under voltageclamp conditions, depolarizing voltage steps up to membrane potentials $20 \mathrm{mV}$ positive to the RMP evoked a persistent net inward current, the amplitude of which was increasing in a nonlinear manner upon enhancement of the step's amplitude. The activation of this inward current yielded an IV-curve endowed with a region of negative slope conductance in the potential range between the RMP $(-75 \mathrm{mV}$ to $-80 \mathrm{mV})$ and -60 to $-55 \mathrm{mV}$. This region of negative slope conductance is sufficient to explain the steady state inward rectification in this potential range observed in these neurons under current-clamp conditions (Stafstrom et al. 1985; for an analytical description of the context between negative slope conductance and inward rectification determined under current-clamp conditions see Finkelstein and Mauro 1977). Depolarizing voltage steps with amplitudes larger than $20 \mathrm{mV}$ elicited, in addition, a transient net inward current $\left(I_{t}\right)$ superimposed on the persistent inward current. The rapid inactivation of the $I_{t}$ (within $100 \mathrm{~ms}$ ) accounts for the time-dependent shape of the IV-curve. When determined at a time corresponding to the time to peak of the $I_{t}(20-$ $60 \mathrm{~ms}$ after onset of the step), a further, nonlinear increase in the negative slope of the IV-curve was observed in the potential range between -60 and $-40 \mathrm{mV}$, i.e. during this time the magnitude of the inward rectification was found to be enhanced. However, in the same potential range the negative slope of the IV-curve measured just before the offset of the voltage step slightly declined, indicating the beginning activation of delayed outward currents. These results obtained from voltage-clamp experiments confirmed the observations made under current-clamp conditions. Using outward current pulses which produced potential changes smaller than $20 \mathrm{mV}$, the slope resistance increased with depolarization independent of the time point of measurement (steady state inward rectification). Upon injection of depolarizing current pulses which evoked potential changes larger than $20 \mathrm{mV}$, a transient depolarizing potential (tDP) occurred, followed by a potential sag. As the amplitude of the tDP increased nonlinearly with the injected current strength, a transient enhancement of the slope resistance could be detected during the first $25-60 \mathrm{~ms}$ after the onset of the current pulse.

A similar response pattern ( $\mathrm{tDP}$ followed by a potential sag) was described for layer $V$ pyramidal cells of the cat neocortex (Stafstrom et al. 1984a). The authors proposed that the tDP is the result of the fast activation of a TTXsensitive, voltage-dependent, persistent sodium current $\left(I_{\mathrm{NaP}}\right)$ which is partially reduced by delayed activated outward currents, thereby producing the potential sag (Stafstrom et al. 1984a, 1985). Our results, however, suggest that the tDP evoked in rat neocortical neurons by the injection of just subthreshold outward current pulses is at least in part an actively generated potential. The arguments in favor of this suggestion are as follows: (1) In the presence of cesium ions and TEA the tDP did not disappear. This would have been the case, if the potential sag was exclusively due to delayed activated potassium outward currents. Still the possibility exists that a cesium- and TEA-insensitive potassium current was responsible for the potential sag. However, although the negative slope conductance measured just before the offset of a voltage step with an amplitude of $30-40 \mathrm{mV}$ was found to decrease with depolarization, the net current was still an inward current (see Fig. 5D), indicating an insignificant activation of outward currents. (2) Under voltage-clamp conditions, a transient inward current $\left(I_{t}\right)$ was detected which was evoked by voltage steps from holding potentials of -80 to $-75 \mathrm{mV}$ (i.e. in the vicinity of the RMP) to command potentials of -40 to $-35 \mathrm{mV}$. This current was not influenced by potassium channel blockers (cesium ions, TEA). The time course of the $I_{t}$ was comparable to the time course of the tDP with a similar time to peak and duration. (3) Both the $I_{\mathrm{t}}$ and the tDP were suppressed by calcium channel blockers (manganese, cobalt, cadmium), indicating that the $I_{\mathrm{t}}$ was due to the activation of a calcium conductance.

In addition to this calcium conductance, we established the presence of a voltage-dependent, persistent sodium current which mainly determines the steady state depolarizing inward rectification in rat neocortical neurons. Upon removal of $\mathrm{NaCl}$ from the ACSF, the steady state inward rectification in depolarizing direction, which was not influenced by calcium channel blockers (see also Connors et al. 1982; Stafstrom et al. 1985), disappeared.

From the presented experimental data, we conclude that the depolarizing inward rectification observed in rat neocortical neurons in vitro in the subthreshold potential range results from the voltage-dependent activation of both a persistent sodium current and a transient calcium current. The persistent sodium current produces a steady state inward rectification, the magnitude of which is transiently enhanced by the activation of a rapidly inactivating calcium current, especially at just subthreshold membrane potentials. The actions of both currents are counterbalanced by instantaneously or delayed activated potassium outward currents, as indicated by the enhancement of the steady state rectification ratio following the injection of cesium ions into the neurons and by the moderate depression of the tDP in the presence of both cesium ions and TEA.

The transient calcium current we described in rat neocortical neurons in vitro resembles, in some aspects, the low-voltage activated calcium current observed in vertebrate sensory neurons (Carbone and Lux 1984; Fedulova et al. 1985): Besides its sensitivity to cobalt and cadmium, it inactivates with time (within $100 \mathrm{~ms}$ ) and with depolarization of the holding potential. A similar calcium current was suggested to be present in CA1 pyramidal cells of the hippocampus (Halliwell and Scholfield 1984; Docherty and Brown 1986), in neurons of the olfactory cortex (Halliwell and Scholfield 1984) and in cerebellar Purkinje cells (Crepel 
and Penit-Soria 1986). Furthermore, the existence of a lowvoltage activated calcium conductance has been inferred (based on results obtained from current-clamp experiments) in guinea pig inferior olivary neurons (Llinás and Yarom $1981 \mathrm{a}, \mathrm{b}$ ), in rat spinal dorsal horn neurons (Murase and Randić 1983), in guinea pig thalamic neurons (Jahnsen and Llinás 1984a, b) and bursting cells of the guinea pig neocortex (McCormick et al. 1985).

Since the suppression of the transient calcium current led to an enhancement of the threshold intensity necessary to evoke an action potential and to an increase in the voltage threshold of the spike, a possible physiological function of such a current may be the regulation of the neuronal excitability. It is important to note that due to the high resting membrane potentials of rat neocortical neurons in vitro $(-75$ to $-80 \mathrm{mV})$, this current is probably activated with every fast depolarizing potential change. Therefore, we suggest that the low-voltage activated, transient calcium current contributes to the determination of the threshold of directly and synaptically evoked action potentials in rat neocortical neurons in vitro.

Acknowledgements. This work was supported by the SFB 220, A5, of the Deutsche Forschungsgemeinschaft. We thank Miss $H$. Harrison for the English revision of the manuscript.

\section{References}

Adams P (1982) Voltage-dependent conductances of vertebrate neurones. TINS 5:116-119

Carbone E, Lux HD (1984) A low voltage-activated calcium conductance in embryonic chick sensory neurons. Biophys J 46:413418

Connors BW, Gutnick MJ, Prince DA (1982) Electrophysiological properties of neocortical neurons in vitro, J Neurophysiol $48 ; 1302-1320$

Constanti A, Galvan M (1983) Fast inward-rectifying current accounts for anomalous rectification in olfactory cortex neurones. J Physiol (Lond) 335:153-178

Constanti A, Galvan M, Franz P, Sim JA (1985) Calcium-dependent inward currents in voltage-clamped guinea-pig olfactory cortex neurones. Pflügers Arch 404:259-265

Crepel F, Penit-Soria J (1986) Inward rectification and low threshold calcium conductance in rat cerebellar purkinje cells. An in vitro study. J Physiol (Lond) 372:1-23

Docherty RJ, Brown DA (1986) Interaction of 1,4-dihydropyridines with somatic Ca currents in hippocampal CA1 neurones of the guinea pig in vitro. Neurosci Lett $70: 110-115$

Fedulova SA, Kostyuk PG, Veselovsky NS (1985) Two types of calcium channels in the somatic membrane of new-born rat dorsal root ganglion neurones. J Physiol (Lond) 359:431 -446

Finkelstein A, Mauro A (1977) Physical principles and formalisms of electrical excitability. In: Kandel ER (ed) Handbook of physiology, section I: The nervous system, vol I, part I, chapt 6 . American Physiological Society, Bethesda, p 161

Franz P, Galvan M, Constanti A (1986) Calcium-dependent action potentials and associated inward currents in guinea-pig neocortical neurons in vitro. Brain Res $366: 262-271$

Hagiwara S, Byerly L (1983) The calcium channel. TINS 6:189193

Halliwell JV, Scholfield CN (1984) Somatically recorded Cacurrents in guinea-pig hippocampal and olfactory cortex neurones are resistent to adenosine action. Neurosi Lett 50:1318

Hotson JR, Prince DA, Schwartzkroin PA (1979) Anomalous inward rectification in hippocampal neurons. J Neurophysiol $42: 889-895$
Howe JR, Sutor B, Zieglgänsberger W (1987a) Baclofen reduces postsynaptic potentials of rat neocortical neurones by an action separate from its hyperpolarizing action. J Physiol (Lond) $384: 539-570$

Howe JR, Sutor B, Zieglgänsberger W (1987b) Characteristics of a long-duration inhibitory post-synaptic potential in rat frontal neocortical neurons in vitro. Cell Molec Neurobiol 7:1-18

Jahnsen H (1986a) Electrophysiological characteristics of neurones in the guinea-pig deep cerebellar nuclei in vitro. J Physiol (Lond) $372: 129-147$

Jahnsen H (1986b) Extracellular activation and membrane conductances of neurones in the guinea-pig deep cerebellar nuclei in vitro. J Physiol (Lond) 372:149-168

Jahnsen H, Llinás R (1984a) Electrophysiological properties of guinea-pig thalamic neurones: an in vitro study. J Physiol (Lond) 349:205-226

Jahnsen H, Llinás R (1984b) Ionic basis for the electroresponsiveness and oscillatory properties of guinea-pig thalamic neurones in vitro. J Physiol (Lond) 349:227-247

Johnston D, Hablitz JJ, Wilson WA (1980) Voltage clamp discloses slow inward current in hippocampal burst-firing neurones. Nature 286:391-393

Llinás R, Sugimori M (1980a) Electrophysiological properties of in vitro purkinje cell somata in mammalian cerebellar slices. $J$ Physiol (Lond) 305:171-195

Llinás R, Sugimori M (1980b) Electrophysiological properties of in vitro purkinje cell dendrites in mammalian cerebellar slices. J Physiol (Lond) 305:197-213

Llinás R, Yarom Y (1981 a) Electrophysiology of mammalian inferior olivary neurones in vitro. Different types of voltagedependent ionic conductances. J Physiol (Lond) 315:549-567

Llinás R, Yarom Y (1981 b) Properties and distribution of ionic conductances generating electroresponsiveness of mammalian inferior olivary neurones in vitro. J Physiol (Lond) 315:569584

Mayer ML, Westbrook GL (1983) A voltage-clamp analysis of inward (anomalous) rectification in mouse spinal sensory ganglion neurones. J Physiol (Lond) 340:19-45

McCormick DA, Connors BW, Lighthall JW, Prince DA (1985) Comparative electrophysiology of pyramidal and sparsely spiny stellate neurons of the neocortex. J Neurophysiol 54:782-806

Murase K, Randić M (1983) Electrophysiological properties of rat spinal dorsal horn neurones in vitro: calcium-dependent action potentials. J Physiol (Lond) 334:141 - 153

Nelson PG, Frank K (1967) Anomalous rectification in cat spinal motoneurons and effect of polarizing currents on excitatory postsynaptic potential. J Neurophysiol 30:1097-1113

Rall W (1969) Time constants and electrotonic length of membrane cylinders and neurons. Biophys J 9:1483-1508

Rall W (1977) Core conductor theory and cable properties of neurons. In: Kandel ER (ed) Handbook of physiology, section 1: The nervous system, volume I, part I, chapt 3. American Physiological Society, Bethesda, p 39

Schwindt P, Crill WE (1980) Properties of a persistent inward current in normal and TEA-injected motoneurons. I Neurophysiol 43:1700-1724

Stafstrom CE, Schwindt P, Flatman JA, Crill WE (1984a) Properties of subthreshold response and action potential recorded in layer $\mathrm{V}$ neurons from cat sensorimotor cortex in vitro. $\mathrm{J}$ Neurophysiol 52:244-263

Stafstrom CE, Schwindt P, Crill WE (1984b) Repetitive firing in layer $\mathrm{V}$ neurons from cat neocortex in vitro. J Neurophysiol $52: 264-277$

Stafstrom CE, Schwindt P, Crill WE (1984c) Cable properties of layer $\mathrm{V}$ neurons from cat sensorimotor cortex in vitro. $J$ Neurophysiol 52:278-289

Stafstrom CE, Schwindt P, Chubb MC, Crill WE (1985) Properties of persistent sodium conductance and calcium conductance of layer V neurons from cat sensorimotor cortex in vitro. J Neurophysiol $53: 153-170$ 
Stevens CF (1980) Ionic channels in neuromembranes: Methods for studying their properties. In: Koester J, Byrne JH (eds) Molluscan nerve cells: From biophysics to behavior. Cold Spring Harbor Reports in the Neurosciences 1:11-31

Sutor B (1986) Nachweis eines GABA-vermittelten, inhibitorischen postsynaptischen Potentials in Neuronen des Neokortex der Ratte (Rattus norvegicus). Ph. D. Thesis, University of Erlangen-Nürnberg
Vogt BA, Gorman ALF (1982) Responses of cortical neurons to stimulation of corpus callosum in vitro. J Neurophysiol $48: 1257-1273$

Received January 2/Accepted May 7, 1987 